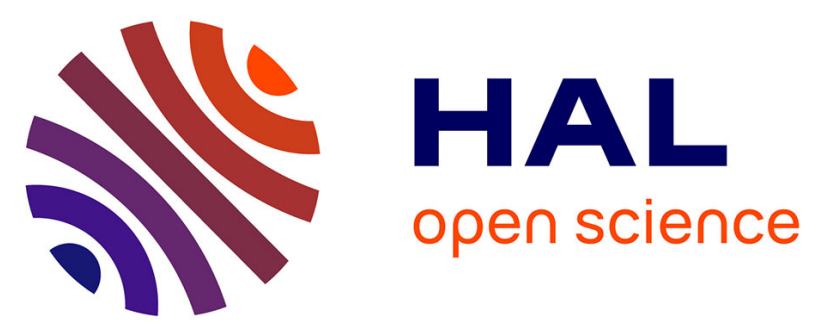

\title{
Photoluminescence of monocrystalline and stain-etched porous silicon doped with high temperature annealed europium
}

R Guerrero-Lemus, A Montesdeoca-Santana, B González-Díaz, B

Díaz-Herrera, J J Velázquez, C Hernández-Rodríguez, E Jiménez-Rodríguez

\section{To cite this version:}

R Guerrero-Lemus, A Montesdeoca-Santana, B González-Díaz, B Díaz-Herrera, J J Velázquez, et al.. Photoluminescence of monocrystalline and stain-etched porous silicon doped with high temperature annealed europium. Journal of Physics D: Applied Physics, 2011, 44 (33), pp.335103. 10.1088/0022$3727 / 44 / 33 / 335103$. hal-00644265

\section{HAL Id: hal-00644265 https://hal.science/hal-00644265}

Submitted on 24 Nov 2011

HAL is a multi-disciplinary open access archive for the deposit and dissemination of scientific research documents, whether they are published or not. The documents may come from teaching and research institutions in France or abroad, or from public or private research centers.
L'archive ouverte pluridisciplinaire HAL, est destinée au dépôt et à la diffusion de documents scientifiques de niveau recherche, publiés ou non, émanant des établissements d'enseignement et de recherche français ou étrangers, des laboratoires publics ou privés. 
Photoluminescence of monocrystalline and stain etched porous silicon doped with high temperature annealed Europium

R. Guerrero-Lemus ${ }^{\mathrm{a},{ }^{*}}$, A. Montesdeoca-Santana ${ }^{\mathrm{a}}$, B. González-Díaz ${ }^{\mathrm{a}}$, B. Díaz-Herrera ${ }^{\mathrm{a}}$, J. J. Velázquez ${ }^{\mathrm{b}}$, C. Hernández-Rodríguez ${ }^{\mathrm{a}}$, E. Jiménez-Rodríguez ${ }^{\mathrm{a}}$

${ }^{a}$ Departamento de Física Básica. Universidad de La Laguna (ULL). Avenida Astrofísico Francisco Sánchez, 2. 38206 La Laguna (Tenerife), España.

${ }^{\mathrm{b}}$ Departamento de Física Fundamental y Experimental, Electrónica y Sistemas. Universidad de La Laguna (ULL). Avenida Astrofísico Francisco Sánchez, 2. 38206 La Laguna (Tenerife), España.

\begin{abstract}
In this work, for the first time the photoluminescent emission and excitation spectra of non-textured layers and stain etched porous silicon layers (PSLs) doped with high temperature annealed Europium (Eu) are evaluated. The PSLs are evaluated as host for rare earth ions and as antireflection coating. The applied doping process, which consists in a simple impregnation method followed by a high temperature annealing step, is compatible with the standard processes in the fabrication of solar cells. The results show down-shifting processes with a maximum photoluminescent intensity at $615 \mathrm{~nm}$, related with the transition ${ }^{5} \mathrm{D}_{0} \rightarrow{ }^{7} \mathrm{~F}_{2}$. Different initial concentrations of $\mathrm{Eu}\left(\mathrm{NO}_{3}\right)_{3}$ were evaluated to study the influence of the rare earth concentration in the photoluminescent intensity. The chemical composition and the morphology of Eu-doped PSLs are examined by means of X-ray Dispersion Spectroscopy, Fourier Transform Infrared Spectroscopy, and Scanning Electron Microscopy. These Eu-doped layers are
\end{abstract}

\footnotetext{
${ }^{*}$ Corresponding author. Tel.: +34 922 318306; fax: +34 922318228. E-mail address:rglemus@ull.es.
} 
considered to be applied as energy converters in silicon-based third generation solar cells.

Keywords: Porous Silicon; Monocrystalline Silicon; Europium doping;

Photoluminescence; Down-Shifting; Solar Cells

Pacs: 68.37.Hk; 78.30.Hv; 78.55.Mb; 88.40.hj

\section{Introduction}

Rare earths ions are being considered as luminescent materials to enhance the performance of solar cells [1]. This improvement can be achieved by means of downconversion, up-conversion, and down-shifting processes. A down-conversion (DC) layer placed on the frontal side of a solar cell can generate two low-energy photons from a high-energy photon, avoiding thermalization losses. Up-conversion (UC) layers are normally placed in the rear side of the solar cell, generating a photon within the silicon band gap, from two low-energy photons. Luminescent down-shifting layers (DS) are formed with the aim of absorbing photons in the 300-500 $\mathrm{nm}$ range, and re-emit them at wavelengths where the solar cell exhibits a higher spectral response [2].

$\underline{\text { In recent works, it has been observed that the } \mathrm{Eu}^{3+} \text { ions can be used to exploit and }}$ down-shift photons under $400 \mathrm{~nm}$ and re-emit them at $612 \mathrm{~nm}$, close to the maximum quantum efficiency wavelength of crystalline silicon based solar cells [3]. This makes $\mathrm{Eu}^{3+}$ ions an ideal candidate to improve the spectral response of crystalline silicon solar cells.

There are several techniques to insert rare earth ions in silicon to produce UC, DC and DS when are used as substrates in solar cells. One of them is placing the rare earth ions 
in the encapsulating polyvinyl acetate (PVA) [3]. Another approach is to incorporate the rare earth ions in the antireflection coating formed on the crystalline silicon substrate $[4$, $5]$.

The incorporation of the rare earth ions in silicon can be carried out by ion implantation [6], electrochemical migration [7] or spark processing [8] and even sol-gel processes [9]. However the high cost of these techniques or the required time of the processes is not adequate for the solar cells fabrication process. For this reason, the thermal doping process is one of the most affordable methods to incorporate $\mathrm{Eu}^{3+}$ in silicon. Other advantages of this thermal process are its simplicity and the ability to easily control diffusion parameters through time and temperature.

However, to obtain a cost-effective doping process in silicon is complicated. One of the most promising alternatives to the conventional silicon doping procedures is to use porous silicon layers (PSLs) $[5,10]$ as rare earth host because of their large surface area, allowing easy penetration of the ions into the matrix. These layers also have antireflection properties, which make them ideal candidates to improve the light absorption in silicon-based optoelectronic devices [11].

PSLs can be formed by electrochemical anodization of silicon in HF-based solutions [12] or stain etching in $\mathrm{HF} / \mathrm{HNO}_{3}$ mixtures [13]. The electrochemical etching of silicon presents some disadvantages for its utilization at industrial level, as the need of high anodic currents [14], and the difficulty of achieving an uniform and protected (from acid infiltration) back-side electrode in large areas to produce electrochemical etching. These disadvantages are not presented in the stain etching process, as the porous layers are formed by simple immersion in the $\mathrm{HF} / \mathrm{HNO}_{3}$ solution [15]. 
The photoluminescent properties of the electrochemically etched porous silicon doped with $\mathrm{Eu}^{3+}$ have been previously studied [16-18]. The incorporation of $\mathrm{Eu}^{3+}$ ions to the substrate consists in two steps, impregnation and annealing, as the method used in this work. But when an electrochemical method is used to produce the PSLs, the impregnation method employed requires longer times, compared to the stain etching process. The oxidation is present in the doping method described in this study for stain etched samples, and it is necessary to enhance the luminescence [4].

In this work the photoluminescent emission (PL) and photoluminescent excitation properties of $\mathrm{Eu}^{3+}$ incorporated in stain etched PSLs and non-textured layers are evaluated for photovoltaic applications, employing a low cost method that could improve the photoconversion efficiency of crystalline silicon solar cells [2].

\section{Experimental}

The PSLs were formed by stain etching of $1 \mathrm{x} 1 \mathrm{~cm}$ p-type $\mathrm{Cz}$ (Czochralski) silicon substrates with resistivity between $0,8-1,2 \Omega \cdot \mathrm{cm}$, in $\mathrm{HF} / \mathrm{HNO}_{3}$ aqueous solution. Low concentration of $\mathrm{HNO}_{3}$ and short etching time were used, in order to assure the homogeneity of the porous surface [19]. After the stain etch process, the samples were rinsed in deionized water, and subsequently dried under $\mathrm{N}_{2}$ flux. The non-textured layers were formed submitting the samples to saw damage etching by immersion in a $\mathrm{NaOH}$ solution.

To dope the PSLs and the non-textured samples, Eu (III) nitrate hexahydrated salt was diluted in pure ethanol to obtain different molar concentrations. The samples were mainly doped with a solution $0,5 \mathrm{M} \mathrm{Eu}\left(\mathrm{NO}_{3}\right)_{3} \cdot 6 \mathrm{H}_{2} \mathrm{O}$. A drop with this solution was deposited in the center of each sample, and homogeneously distributed across the surface by a spin-on procedure. 
Finally, the samples were submitted to a thermal process in a conventional furnace, at $850^{\circ} \mathrm{C}$ for $50 \mathrm{~min}$. Although other diffusion temperatures and times have proven to be efficient to incorporate and activate rare earth ions in silicon [4], only parameter ranges suitable to be introduced in a solar cell fabrication process were chosen to study the PL properties.

The chemical composition of the stain etched PSLs was analyzed by means of a Fourier Transform infrared spectrometer (FTIR) model Bruker Tensor 27, using $4 \mathrm{~cm}^{-1}$ resolution. The elemental composition and the morphology of the Eu-doped stain etched PSLs were examined by means of X-ray dispersion spectroscopy (EDS) and scanning electron microscopy (SEM) in a JEOL 6300 electron microscope.

The UV-Vis photoluminescence measurements were obtained exciting the samples with light from a $300 \mathrm{~W}$ Xe arc lamp, passed through a 0,25 m double-grating monochromator and detected with a $0,25 \mathrm{~m}$ monochromator and a photomultiplier tube. All spectra were acquired at room temperature. To compare the PL intensities, a sample holder was used to assure the same emplacement of the samples, the optical path was kept unaltered and the monochromator slits remained unchanged. The total hemispherical reflectance was measured with a Varian 500 spectrometer equipped with an integrating sphere.

To calculate the internal quantum efficiency (IQE), light selected in different spectral ranges by a set of filters was focused on the samples, and the short circuit current was measured by an amplifier which adjusts a zero voltage directly at the sample. Furthermore, the setup included some bias light lamps, which produced an additional steady state white light illumination with the aim of achieving the standard operating conditions of a solar cell. 


\section{Results and discussion}

The FTIR spectra in figure 1 show the absorption bands corresponding to the vibrational modes of the Si-O bonds at $1100 \mathrm{~cm}^{-1}$ and $1185 \mathrm{~cm}^{-1}$ for Eu-doped PSLs, and at 1078 $\mathrm{cm}^{-1}$ for the Eu-doped non-textured layer. The shift and broadening of the Si-O absorption band for Eu-doped PSLs are the result of a combination of the asymmetric stretching of the LO3-TO3 mode [20] and the inverted oxide LO4-TO4 mode [21], which confirms the amorphous characteristics of the $\mathrm{SiO}_{2}$ on the surface. Besides, the peak from the non-textured layer at $1078 \mathrm{~cm}^{-1}$ corresponds to the $\mathrm{Si}-\mathrm{O}$ vibrational mode [22], which confirms the presence of a highly ordered $\mathrm{SiO}_{2}$. This oxidized silicon acts as a host for activated $\mathrm{Eu}^{3+}$ ions, contributing to the transition ${ }^{5} \mathrm{D}_{0} \rightarrow{ }^{7} \mathrm{~F}_{2}$. Also the ordered $\mathrm{SiO}_{2}$ produces the splitting of the $\mathrm{PL}$ at $615 \mathrm{~nm}$, detected in figure 2.

A SEM image of a Eu-doped PSLs surface with the maximum initial nitrate solution at $1500 x$ is shown in figure 3 (a). As the result of the spin-on process, the surface is completely covered by the nitrate solution which, after the thermal process, is also covered by residual salts. To incorporate this process to a photovoltaic manufacturing line, it is necessary a silicon surface completely free of residual salts from the rare earth doping process, to place the electrical contacts and the passivation layer. Consequently, PSLs Eu-doped with the same procedure were cleaned in order to remove the residual salts and it is shown in figure 3 (b). This cleaning procedure could also enlarge the pore size on the silicon surface, as it is observed comparing figures 3 (a) and 3 (b).

The EDS spectrum of figure 4 shows the elemental composition of the Eu-doped PSLs after the cleaning process. The Eu peaks observed confirm the presence of $\mathrm{Eu}^{3+}$ ions over the PSLs surface, and the presence of $\mathrm{F}$ is derived from the HF acid used to remove the oxide layer formed during the cleaning process. 
Figure 2 also shows the normalized emission spectra of the $\mathrm{Eu}^{3+}$ optically activated in the PSLs and in non-textured samples. The spectra were measured in the range of 450 to $750 \mathrm{~nm}$, upon excitation of the ${ }^{5} \mathrm{~L}_{6}$ level (at $394 \mathrm{~nm}$ ). All the observed peaks are attributed to the transitions from the ${ }^{5} \mathrm{D}_{0}$ level to the spin-orbit states of ${ }^{7} F_{j}(j=1,2,3,4)$. Unlike the $\mathrm{Eu}^{3+}$ doped PSLs formed by electrochemical anodization [16], there is no emission corresponding to the ${ }^{5} \mathrm{D}_{0} \rightarrow{ }^{7} \mathrm{~F}_{0}$ transition, characteristic of high crystalline substrates, like silicon nanocrystallites [16]. There are no appreciable emissions corresponding to transitions ${ }^{5} \mathrm{D}_{1,2} \rightarrow{ }^{7} \mathrm{~F}_{\mathrm{j}}$ between 450 and $570 \mathrm{~nm}$, indicating that the dominant relaxation process among the ${ }^{5} \mathrm{D}_{\mathrm{j}}$ levels in these silicon substrates is the multiphonon de-excitation [9]. The emission bands are within the $575-725 \mathrm{~nm}$ range, where the crystalline silicon solar cells present an optimum spectral response [2]. Also, there are not intraconfigurational $4 \mathrm{f}-4 \mathrm{f}$ transitions from the ground ${ }^{7} \mathrm{~F}_{0}$ level that absorb light between 550 and $1100 \mathrm{~nm}$, so the wavelengths in the regions of the solar spectrum that are not down-shifted are transmitted to the underlying substrate.

The most intense peak at $615 \mathrm{~nm}$ in Eu-doped PSLs and $611 \mathrm{~nm}$ in the non-textured layer corresponds to the ${ }^{5} \mathrm{D}_{0} \rightarrow{ }^{7} \mathrm{~F}_{2}$ transition. This transition is hypersensitive to the local environment of the $\mathrm{Eu}^{3+}$ ions, and it could be used as a spectroscopic probe of the environments around the $\mathrm{Eu}^{3+}$ ions. As a consequence, the changes in this transition in the non-textured layer reveals the existence of optically activated $\mathrm{Eu}^{3+}$ in sites with different symmetries, due to differences in the local symmetry around the $\mathrm{Eu}^{3+}$ ions $[8$, 23]. This result could indicate that activation of $\mathrm{Eu}^{3+}$ ions in the non-textured layer occurs not only in the crystalline silicon matrix, but also in the top oxide layer formed during the thermal process [4]. The ${ }^{5} \mathrm{D}_{0} \rightarrow{ }^{7} \mathrm{~F}_{2}$ transition in the PL spectrum of the PSLs is wider and does not split, suggesting that the activation of $\mathrm{Eu}^{3+}$ ions occurs in a large variety of sites: the crystalline silicon matrix and different sites in the amorphous layer 
formed on the surface of the PSLs [24]. This result differs from the same transition in the emission spectrum of $\mathrm{Eu}^{3+}$ doped PSLs formed by electrochemical anodization [16], which present a ${ }^{5} \mathrm{D}_{0} \rightarrow{ }^{7} \mathrm{~F}_{0}$ transition split.

Figure 5 shows a comparison of the $\mathrm{Eu}^{3+}$ photoluminescent emission intensities for the Eu-doped substrates under study, upon excitation at $394 \mathrm{~nm}\left({ }^{7} \mathrm{~F}_{0} \rightarrow{ }^{5} \mathrm{~L}_{6}\right.$ transition). The integrated intensity ratio of the non-textured layer and stain etched PSLs emission spectra between 550 and $750 \mathrm{~nm}$ is 12,51 . The inset in Figure 5 shows the reflectance spectra of the undoped stain etched PSLs and the non-textured layer. As it can be observed, the reflectance values between 300 and $550 \mathrm{~nm}$ are very low for the stain etched PSLs, producing larger absorption of the high-energy photons that can be photoconverted than for the non-textured layer [25]. On the other hand, several studies of external quantum efficiency from light-emitting diodes with textured surface [26, 27] demonstrate that the texturing of the semiconductor surfaces increases the external quantum efficiency. Consequently, we conclude that the internal PL is lower for the Eudoped stain etched PSLs compared to the non-textured sample. This conclusion would indicate that most of the $\mathrm{Eu}^{3+}$ ions incorporated in the stain etched PSLs have not been activated or their photoluminescence has been quenched [28].

Figure 6 shows the integrated PL intensity of Eu-doped PSLs samples as a function of the initial concentration of the europium nitrate solution. The PL intensity increases, and shows no evidence of a concentration quenching effect in a wide range of initial molar concentrations. The intensity has an exponential dependence with the initial $\mathrm{Eu}^{3+}$. However, for concentrations higher than those of figure 6 , the deposited solution drop is not spreading over the whole sample in the spin-on procedure, due to its high viscosity. Further experiments should be carried out to decrease the solution viscosity in order to increase the Europium concentration using spin-on processes. 
The excitation spectra of the $\mathrm{Eu}^{3+}$ doped PSLs and non-textured layers, measured between 300 and $550 \mathrm{~nm}$ are shown in Figure 7. The excitation spectrum corresponding to the stain etched and Eu-doped PSLs was normalized to the ${ }^{7} \mathrm{~F}_{0} \rightarrow{ }^{5} \mathrm{~L}_{6}$ transition (395 $\mathrm{nm}$ ), and measured at $\lambda_{\mathrm{em}}=615 \mathrm{~nm}$, where it presents the maximum photoluminescent intensity, and the excitation spectrum corresponding to the Eu-doped non-textured sample was normalized to the ${ }^{7} \mathrm{~F}_{0} \rightarrow{ }^{5} \mathrm{D}_{2}$ transition $(465 \mathrm{~nm})$, and measured at $\lambda_{\text {em }}=611$ $\mathrm{nm}$ (also at its maximum photoluminescent intensity). For both stain etched PSLs and non-textured samples, the excitation spectra present characteristic bands corresponding to the ${ }^{7} \mathrm{~F}_{0} \rightarrow{ }^{5} \mathrm{H}_{4},{ }^{7} \mathrm{~F}_{0} \rightarrow{ }^{5} \mathrm{D}_{4},{ }^{7} \mathrm{~F}_{0} \rightarrow{ }^{5} \mathrm{G}_{2},{ }^{7} \mathrm{~F}_{0} \rightarrow{ }^{5} \mathrm{~L}_{6},{ }^{7} \mathrm{~F}_{0} \rightarrow{ }^{5} \mathrm{D}^{3},{ }^{7} \mathrm{~F}_{0} \rightarrow{ }^{5} \mathrm{D}_{2}$ and ${ }^{7} \mathrm{~F}_{0} \rightarrow$ ${ }^{5} \mathrm{D}_{1}$ transitions.

To evaluate which sample can offer a higher contribution to the enhancement of a solar cell efficiency, the increase of the e-h pairs produced by the down-shifting process in a crystalline silicon solar cell has been approximated considering only the emission at the maximum photoluminescent intensities at $615 \mathrm{~nm}$ for stain etched Eu-doped PSLs and $611 \mathrm{~nm}$ for the Eu-doped non-textured layer.

The photons down-shifted to $615 \mathrm{~nm}$ and $611 \mathrm{~nm}$ by the Eu doped PSLs and the Eudoped non-textured layer, respectively, have spectral distributions that can be determined by the excitation spectra.

Taking into account this spectral distribution of down-shifted photons and a typical internal quantum efficiency (IQE) of a crystalline solar cell, it could be estimated the gain of photons in the range of $350-550 \mathrm{~nm}$ that are converted in electron-hole pairs with respect to the non doped layers.

Then, the IQE is defined as the relation between the e-h pairs produced and the incident non-reflected photons, as function of the wavelength $\lambda$ : 
$\operatorname{IQE}(\lambda)=\frac{N(\lambda)}{\varphi(\lambda)}$

where $N(\lambda)$ is the density of e-h pairs generated and $\varphi(\lambda)$ is the density of incident nonreflected photons.

As the incident photons are transformed to down-shifted photons at 615 and $611 \mathrm{~nm}$ for Eu-doped PSLs and non-textured layers, respectively, the e-h pairs produced by these down-shifted photons can be estimated with equation (1) for both Eu-doped layers:

$N_{E u, P S L}(\lambda)=\varphi_{E u, P S L}(\lambda) \cdot \operatorname{IQE}(615 \mathrm{~nm})$

$N_{E u, \text { non-textured }}(\lambda)=\varphi_{E u, \text { non-textured }}(\lambda) \cdot \operatorname{IQE}(611 \mathrm{~nm})$

Consequently, the increase of e-h pairs due to down-shifting processes in the $350-550$ $\mathrm{nm}$ spectral range can be estimated for the $\mathrm{Eu}^{3+}$ doped stain etched PSLs by:

$\frac{N_{E u, P S L}}{N_{P S L}}=\frac{\int_{350}^{550} \varphi_{E u, P S L}(\lambda) \cdot \operatorname{IQE}(615 \mathrm{~nm}) d(\lambda)}{\int_{350}^{550} \varphi_{E u, P S L}(\lambda) \cdot \operatorname{IQE}(\lambda) d(\lambda)}$

and for the $\mathrm{Eu}^{3+}$ non-textured layer:

$\frac{N_{E u, \text { nontextured }}}{N_{\text {non-textured }}}=\frac{\int_{350}^{550} \varphi_{E u, \text { non-textured }}(\lambda) \cdot \operatorname{IQE}(611 \mathrm{~nm}) d(\lambda)}{\int_{350}^{550} \varphi_{\text {Eu,non-textured }}(\lambda) \cdot \operatorname{IQE}(\lambda) d(\lambda)}$

The IQE spectrum employed for the calculations is shown in figure 8 (a), and it corresponds to a typical crystalline silicon solar cell [29]. The increment of e-h pairs generated by down-shifting processes by the $\mathrm{Eu}^{3+}$ stain etched doped PSLs and nontextured layer compared to the non-doped ones are shown in figure 8 (b), and have been calculated with equations 4 and 5, integrating numerically. Then, for the stain etched 
Eu-doped PSLs, the estimated increment in e-h pairs generated by the fraction of the photons down-shifted by the $\mathrm{Eu}^{3+}$ photoconversion layer (to $615 \mathrm{~nm}$ ) is $+35,46 \%$ compared to non-Eu-doped PSLs, and for the Eu-doped non-textured layer (to $611 \mathrm{~nm}$ ) is $+25,65 \%$ compared to a non-Eu-doped non-textured sample.

It should be taken into account that these quantitative results are an estimation of the maximum percentage of IQE increment that could be obtained for the light in the spectral range down-shifted by europium in doped cells compared to non-doped ones. In a more complex model, other factors could play a role as, for example, the interaction of europium ions and the silicon nanostructures embedded in the PSLs and the possible recombination processes through the introduction of energy levels in the band gap, which should be further studied.

\section{Conclusions}

In this paper, a novel low cost and compatible method with the silicon-based solar cells fabrication procedure has been employed in order to incorporate and optically activate $\mathrm{Eu}^{3+}$ ions into a layer with antireflection properties formed by acid texturization and into a non-textured layer.

The excitation and emission spectra show that these layers absorb high energy photons, between 300 and $550 \mathrm{~nm}$, and down-shift them to wavelengths close to the maximum quantum efficiency wavelength of crystalline silicon solar cells. Consequently, this process may improve the spectral response of this type of solar cells.

There is no evidence of quenching effect on the emission intensity within the range of $\mathrm{Eu}^{3+}$ doping concentrations studied. Also, the PL intensity in Eu-doped PSLs has an 
exponential dependence with the $\mathrm{Eu}^{3+}$ concentration. Thus, the PSLs are adequate $\mathrm{Eu}^{3+}$ hosts, allowing the penetration by thermal diffusion of $\mathrm{Eu}^{3+}$ ions.

On the other hand, the down-shifting effect of $\mathrm{Eu}^{3+}$ can enlarge the internal quantum efficiency of a silicon-based solar cell with stain etched Eu-doped PSLs on the front side compared to the same solar cell with a Eu-doped non-textured layer on the front side. However, in our experiments the higher photoluminescent intensity corresponds to the Eu-doped non-textured layers, suggesting that a lower quantity of ions has been optically activated in the PSLs compared to the non-textured layers. Further experiments should be carried out in order to increase the photoluminescent intensity of the Eu-doped PSLs.

\section{Acknowledgments}

This work has been supported by the Ministerio de Ciencia e Innovación, Spain (Projects ENE2007-60720/ALT and ENE2010-14865/ALT), co-supported by the European Social Fund, the 2007 Research Program of Gobierno Autónomo de Canarias (PI2007-010), and Agencia Canaria de Investigación, Innovación y Sociedad de la Información (FPI).

\section{References}

[1] Strümpel, M. McCann, G. Beaucarne, V. Arkhipov, A. Slaoui, V. Svrcek, C. del Cañizo and I. Tobias, Sol. Energy Mat. Sol. Cells 91 (2007) 238-249. 
[2] E. Klampaftis, D. Ross, K.R. McIntosh, B.S. Richards, Sol. Energy Mater. Sol. Cells 93 (2009) 1182-1194.

[3] A.L. Donne, M. Acciarri, D. Narducci, S. Marchionna, Binetti, Prog. Photovolt. Res. Appl. 17 (2009) 519-525.

[4] B. González-Díaz, B. Díaz-Herrera, R. Guerrero-Lemus, J. Méndez-Ramos, V.D. Rodríguez, C. Hernández-Rodríguez, J.M. Martínez-Duart, Mater. Sci. Eng. B. 146 (2008) 171-174.

[5] B. Díaz-Herrera, B. González-Díaz, R. Guerrero-Lemus, C. Hernández-Rodríguez, J. Méndez-Ramos and V.D. Rodríguez, Physica E 41 (2009) 525-528.

[6] F. Namavar, F. Lu, C.H. Perry, A. Cremins, N.M. Kalhoran, J.T. daly, R.A., Soref, Mater. Res. Soc. Symp. Proc. 358 (1995) 375-379.

[7] T. Kimura, A. Yokoi, H. Horiguchi, R. Sato, T. Ikoma, A. Sato, Appl. Phys. Lett. 65 (1994) 983-985.

[8] St. John, J; Coffer, J.; Rho, Y.; Pinizzotto, Appl. Phys. Lett 68 (1996) 3416-3418.

[9] Q. Lu, Z. Wang, P. Wang, J. Li, Nanoscale Res. Lett. 5 (2010) 761-768.

[10] A. Moadhen, H. Elhouichet, B. Canut, C.S. Sandu, M. Oueslati, J.A. Roger, Mater. Sci. Eng., B 105 (2003) 157-160.

[11] I. Moon, K. Kim, M. Thamilselvan, Y. Kim, K. Han, D. Kyeong, T. Kwon, D.V. Ai, J. Lee, M Ju, K. Lee, J. Yi, Sol. Energy Mater. Sol. Cells 93 (2009) 846-850.

[12] D.R. Turner, J. Electrochem. Soc., 105 (1958) 402-408.

[13] B. Schwartz, H. Robbins, J. Electrochem Soc., 106 (1959) 505-508. 
[14] V.Y. Yerokhov, R. Hezel, M. Lipinski, R. Ciach, H. Nagel, A. Mylyanych, P. Panek, Sol. Energy Mater. Sol. Cells, 72 (2002) 291-298.

[15] R. Guerrero-Lemus, C. Hernández-Rodríguez, F. Ben-Hander and J.M. MartínezDuart, Sol. Energy Mater. Sol. Cells 72 (2002) 495-501.

[16] A. Moadhen, H. Elhouichet, M. Oueslati, M. Férid, J. Lumin., 99 (2002) 13-17.

[17] A. Moadhen, H. Elhouichet, B. Canut, C.S. Sandu, M. Oueslati, J.A. Roger, Mater. Sci. Eng. B. 105 (2003) 157-160.

[18] H. Elhouichet, M. Oueslati, Phys. Stat. Sol. (a), 204 (2007) 1497-1501.

[19] B. González-Díaz, R. Guerrero-Lemus, N. Marrero, C. Hernández-Rodríguez, F.A. Ben-Hander, J.M. Martínez-Duart, J. Phys. D 39 (2006) 631-634.

[20] P. Lange, U. Schnakenberg, S. Ullerich, and H.-J. Schliwinski, J. Appl. Phys. 68 (1990) 3532-3537.

[21] P. Grosse, B. Harbecke, B. Heinz, R. Meyer, and M. Offenberg, Appl. Phys. A 39 (1986) 257-268.

[22] P.J. Launer, Silicon Compounds Register and Review, Petrarch Systems Silanes and Silicones, Petrarch Systems, Bristol, 1987.

[23] R. Reisfeld et al, Struct. Bonding (Berlin) 13, (1973) 53.

[24] E. Vazsonyi, E. Szilagyi, P. Petrik, Z.E. Horvath, T. Lohner, M. Fried, G. Jalsovszky, Thin Solid Films 388 (2001) 295-302.

[25] R. Guerrero-Lemus, F. Ben-Hander, C. Hernández-Rodríguez, J. M. MartínezDuart, Mat. Sci. Eng. B 101 (2003) 249-254. 
[26] I. Schnitzer, E. Yablonovitch, C. Caneau, T.J. Gmitter, A. Scherer, Appl. Phys. Lett. 63 (1993) 2174-2176.

[27] H.C. Lee, J.B. Park, J.W. Bae, P.T.T. Thuy, M.C. Yoo, G.Y. Yeom, Solid State Electron., 52 (2008) 1193-1196.

[28] M. Nogami and Y. Abe, J. Non-Cryst. Solids 197 (1996) 73-78.

[29] B. González-Díaz, R. Guerrero-Lemusa, B. Díaz-Herrera, N. Marrero, J. MéndezRamos, Dietmar Borchert, Mat. Sci. Eng. B 159-160 (2009) 295-298. 


\section{Figure captions}

Figure 1: FTIR transmission spectra of $\mathrm{Eu}^{3+}$ stain etched doped PSLs and a nontextured Si layer.

Figure 2: Photoluminescence spectra excited at $\lambda_{\mathrm{ex}}=394 \mathrm{~nm}$ of stain etched Eu-doped PSLs and a Eu-doped non-textured layer. The intensities of the PL are normalized to the respective main emission peak ${ }^{5} \mathrm{D}_{0} \rightarrow{ }^{7} \mathrm{~F}_{2}$ for comparative purposes. The samples were doped with an initial concentration of $0,5 \mathrm{M} \mathrm{Eu}\left(\mathrm{NO}_{3}\right)_{3} \cdot 6 \mathrm{H}_{2} \mathrm{O}$.

Figure 3: SEM images of (a) the stain etched Eu-doped PSLs surface just after the diffusion process and (b) the same surface after the cleaning process.

Figure 4: EDS spectrum of the stain etched Eu-doped PSLs after the cleaning process.

Figure 5: Comparison of photoluminescence emission intensities of stain etched Eudoped PSLs and a Eu-doped non-textured layer. The inset shows the reflectance spectra of both undoped substrates between 300 and $1200 \mathrm{~nm}$. The samples were doped with an initial concentration of $0,5 \mathrm{M} \mathrm{Eu}\left(\mathrm{NO}_{3}\right)_{3} \cdot 6 \mathrm{H}_{2} \mathrm{O}$.

Figure 6: Evolution of the PL intensity for the stain etched Eu-doped PSLs samples as a function of the molar concentration $(\mathrm{M})$ of $\mathrm{Eu}^{3+}$ in the initial nitrate solution.

Figure 7: Photoluminescent excitation spectra for stain etched Eu-doped PSLs $\left(\lambda_{\mathrm{em}}=\right.$ $615 \mathrm{~nm})$ and for a Eu-doped non-textured layer $\left(\lambda_{\mathrm{em}}=611 \mathrm{~nm}\right)$. The intensities of the PL are normalized to the transition ${ }^{7} \mathrm{~F}_{0} \rightarrow{ }^{5} \mathrm{~L}_{6}$. The samples were doped with an initial concentration of $0,5 \mathrm{M} \mathrm{Eu}\left(\mathrm{NO}_{3}\right)_{3} \cdot 6 \mathrm{H}_{2} \mathrm{O}$.

Figure 8: (a) IQE spectrum of a typical crystalline silicon solar cell; and (b) e-h pairs generated from photons in the range of $350-550 \mathrm{~nm}$ that are transformed to $615 \mathrm{~nm}$ 
photons by the stain etched Eu-doped PSLs, and to $611 \mathrm{~nm}$ by the Eu-doped nontextured sample. 